\title{
LA MENOR EDAD EN LOS POEMAS HOMÉRICOS
}

This paper is a study of the various aspects of infancy, boyhood and girlhood in Homer. Firstly, of the terminology and the child psychology revealed in the poems. Secondly, of views on childhood, family scenes, breeding, the relationships between parents and their children, children and war and scenes of infants play in the open. Lastly, what might be described as the earliest courtships of adolescence, amongst other aspects.

With some involvement of myth related to the subject, there are depictions of life and basic psychology evident in the homeric poems. The Iliad appears, relative to its length, richer regarding the subject of children compared with the Odyssey. It contains detail, which although complementary to that of the Odyssey. shows a clear contrast in nature and meaning.

Sabido es que estos dos grandes poemas han experimentado un largo y complicado proceso de formación y que, en la forma que conocemos, representan el punto de llegada de una dilatada tradición de poesía oral. Como consecuencia, la Iliada y la Odisea, sean cuales sean fecha y responsable de la redacción última, ofrecen un cuerpo narrativo recompuesto, estratificado, de engarces y recursos formularios ' , en que hay elementos muy antiguos junto a otros de tiempo cercano al montaje final $y$, naturalmente, de momentos intermedios. La utilización de Homero perdiendo de vista esta ya adquirida evidencia supone, teóricamente, un abuso. Intentar, sin embargo, proceder a la disección de los poemas para disponer cada elemento en su cronologia, su contexto y su significación más ajustados es imposible aventura, cuyos resultados resbalarian entre lo subjetivo y lo arbitrario. Pienso, pues, que un recorrido sobre los poemas homéricos en pregunta de tema concreto debe par-

1 Ahi están los fundamentales articulos (1928-1948) de M. Parry, recogidos en The Making of Homeric Verse, Oxford 1971. Bibliografia posterior sobre el particular en M. S. Jensen, The Homeric Question and the Oral-Formulaic Theory, Copenhague 1980 . 
tir de la unitariedad que en la redacción última presentan, sobreentendiendo que los datos extraidos corresponden a ese amplio período de varios siglos durante el que los poemas se formaron hasta dar en lo que son. Lo que quiero decir es que me parece lícito rescatar de los poemas un cuadro de la sociedad homérica, a pesar de que esa sociedad responda a un minimo de cinco centurias y que a lo largo de tan dilatado tiempo haya podido haber notable evolución. Y, como se puede ver, no tomo partido, porque no es preciso, en la discusión sobre si existió o no una sociedad homérica histórica, entendida como unitariamente derivada de un periodo concreto; y estoy pensando en la vieja polémica que tiene sus últimas manifestaciones en el desacuerdo de los grandes helenistas británicos, filólogo y arqueólogo respectivamente, Adkins y Snodgrass ${ }^{2}$.

Tengo lo dicho por aplicable al tema de las primeras enfermedades de la vida del hombre en Homero, que es aspecto indiscutiblemente social. Resulta comprensible que para tal objeto encontremos dificultades en orden a una disposición de testimonios en diacronía, fundamentalmente porque la primera distinción en Homero se establece entre la pervivencia micénica y lo que es posterior, siendo así que lo que los poemas nos presentan al respecto de los menores son cuadros de vida y psicologia rudimentaria en circunstancias diversas, y muy poco de política y de instituciones, realidades estas últimas las que más transformadas se vieron con el fenómeno de la caida de los palacios y sus largas secuelas. Nos las vemos, consecuentemente, con un aspecto susceptible cuando menos de amplia continuidad, lo que hace poco de lamentar la inviabilidad en Iliada y Odisea de cualquier ensayo disecatorio minucioso y ajustado.

Los términos que con más frecuencia usan los poemas para referirse

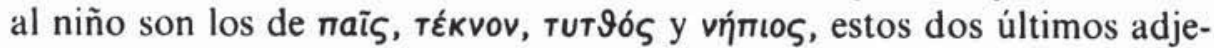
tivos susceptibles de empleo absoluto ${ }^{3}$. Otras palabras familiares al poe-

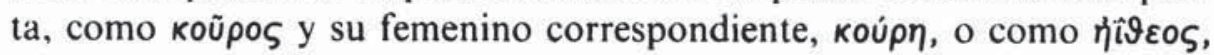
no apuntan de forma invariable al particular de nuestro tema, en cuanto que aplicables a jóvenes formados y por ende virtualmente adultos ${ }^{4}$;

2 A. H. W. Adkins, "Homeric Values and Homeric Society», JHS 91, 1971, páginas 1-14, y A. M. Snodgrass, "An Historical Homeric Society», JHS 94, 1974, pp. $115-125$.

"Para este segundo término es fundamental el estudio de S. Edmunds, Homeric vímios, diss. Harvard 1976.

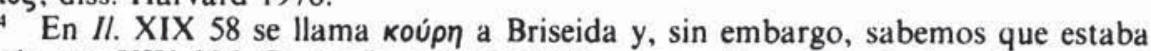
casada por XIX 295. Se puede entender $\eta \hat{i} \vartheta \varepsilon o \iota$ como jóvenes todavia solteros, cual hace G. Wickert-Micknat, Die Frau (Archaeologia Homerica III R), Gotinga 1982, 


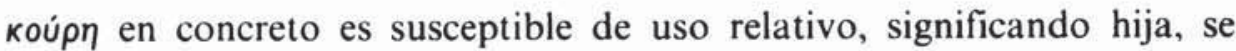
trate de joven muchacha y doncella, se trate de mujer casada ${ }^{5}$. En

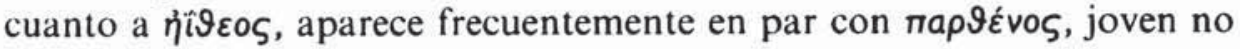

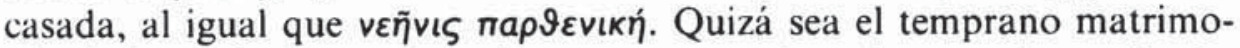
nio de la mujer lo que permita aceptar que la veñvıs sea la muchacha recién salida de la niñez ${ }^{6}$. Los muy frecuentes comparativo y superlati-

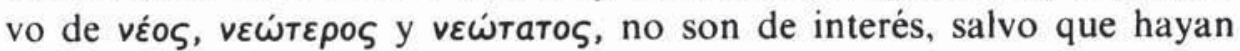
perdido su sentido relativo de 'más joven que otro' o 'el más joven entre varios' para significar 'muy joven, jovencísimo'. Tal es el caso de

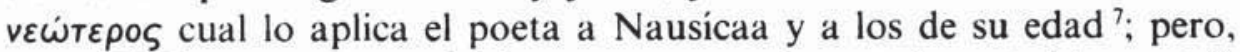
aun asi, el contexto permitiria una extrema juventud postadolescente ${ }^{8}$. De $т \eta \lambda u ́ \gamma \varepsilon т о \varsigma$ son aprovechables sólo los casos en que el contexto sugiere que se hace alusión a un benjamín de familia todavía niño ${ }^{9} \mathrm{o}$ a un

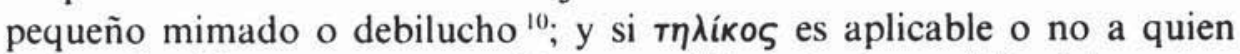
está en la niñez, es cosa que sólo es posible deducir también del contex-

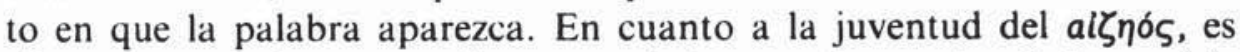
plenamente madura y por lo tanto adulta, con lo que la edad sugerida por el término excede con mucho de la que aquí interesa ". Contraria-

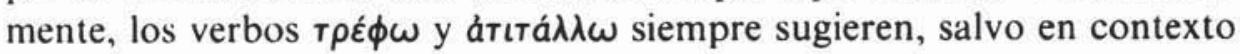
de cuidado de animales, la crianza y educación de un menor de edad.

Lo que a nosotros nos interesa aqui son las edades previas al alcance de la $\ddot{\eta} \beta \eta$, o condición de hombre y mujer físicamente hechos. Quizá

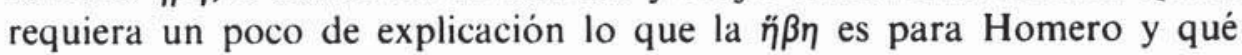

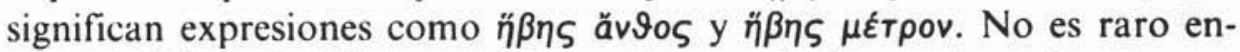

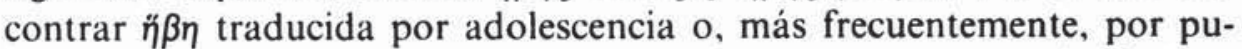
bertad; y sólo muy particularmente es admisible tal traducción ${ }^{12}$. Si se

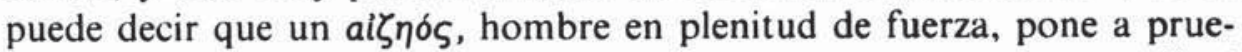
ba su $\eta \beta \eta^{13}$; si leemos que un guerrero al morir abandona su $\eta^{\prime} \beta \eta^{14}$; si

p. 9, quien además los relaciona con la tropa, de lo que no encuentro evidencia. En p. 29 los tiene simplemente por solteros.

Wickert-Micknat, Die Frau, p. 114.

6 Wickert-Micknat, Die Frau, p. 114.

7. Od. VII 293-294.

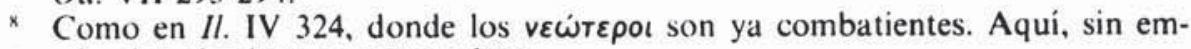
bargo, el valor absoluto es menos claro.

Asi Orestes, en Il. IX 143 y 285.

10. Es el caso de II. XIII 470.

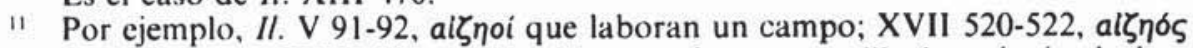

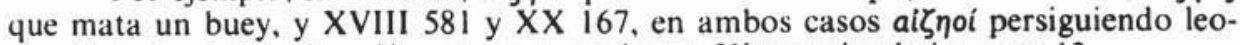
nes. Se trata de hombres jóvenes pero maduros. Véase más abajo, nota 13.

1: Se aplica a adolescentes en II. XXIV 347-348 y Od. X 277-279.

11 II. XXIII 432. Es inapropiada la traducción de J. Duchemin, "Aspects pastoraux de la poésie homérique. Les comparations dans l'lliade», REG 73, 1960 , 
de Telémaco, que ha superado la cota de los veinte años, se puede decir

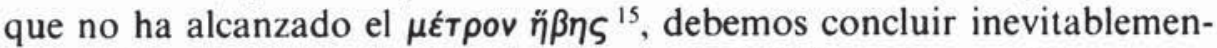
te que $\ddot{\eta} \beta \eta$ no es ni adolescencia ni pubertad. Sí lo es la $\pi \rho \omega \vartheta \eta \dot{\beta} \eta$, es decir, la $\ddot{\eta} \beta \eta$ incipiente, sustantivo no atestiguado salvo en variantes adje-

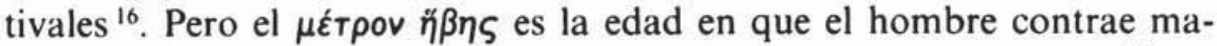
trimonio ${ }^{17}$, en que es ya considerado una persona mayor, $\mu \varepsilon$ ya ${ }^{18}$, en que puede recibir para administrar por sí mismo parte de la herencia fa-

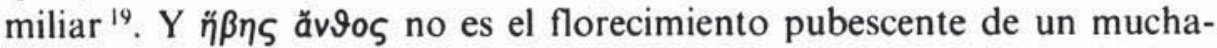
cho, sino la juventud madura de un Eneas, vigoroso guerrero, casado y padre $^{20}$. La $\eta \ddot{\eta} \eta$ es, pues, la edad en que la persona alcanza la condición de adulta $y$, por lo tanto, ha llegado al máximo de sus posibilidades fisicas, intelectuales y de actuación social; la edad del guerrero cumplido ${ }^{21}$. Es el sentido evidente de $\eta \hat{\beta} a \dot{\omega} \omega$ en el lamento de Néstor sobre su juventud perdida ${ }^{22}$.

Las edades anteriores, las que interesan aqui, se caracterizan por las notas contrarias a las dichas. Homero funciona con algunos tópicos en este sentido, configurando al niño y al adolescente a través de notas que resaltan la inmadurez propia de la tierna edad en sus más variadas manifestaciones. Desde la inseguridad hasta la incapacidad para el combate; desde la indefensión hasta la falta de buen sentido; desde la carencia de autocontrol hasta las limitaciones frente a tareas de responsabilidad. Los poemas homéricos son generosos, en lo que cabe, a la hora de brin-

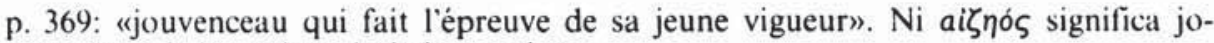
venzuelo, ni $\ddot{\eta} \beta \eta$ quiere decir joven vigor.

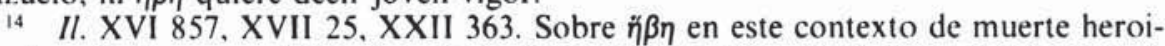
ca, véase N. Loraux, " $" H \beta \eta$ et ávopia: deux versions de la mort du combattant athénien", Ancient Society 6, 1975, p. 23.

15 Od. IV 668; asi lo dice Antinoo. Contrariamente, Penélope considera que su

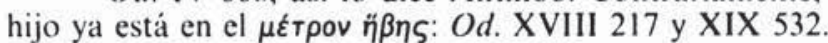

16 Il. VIII $518, O d$. I 431 y VIII 263.

17 II. XI 225.

is Od. XIX 532.

19) Od. XIX 409-4I2.

20 II. XIII 484; cf. B. Mader, art. "ăvঐos", 3-3a, en B. Snell-H. Erbse (edd.), Lerikon des frühgriechischen Epos, col. 876.

"J.-P. Vernant, "La belle mort et la cadavre outragé», La mort, le's morts dans les sociétés anciennes, Cambridge-Paris 1982, p. 57. El aducido valor de $\eta \not \beta \eta$ persiste, sin apenas oscilación, en los líricos arcaicos, como muy bien ha visto y justifica M. Vilchez, "Sobre los periodos de la vida humana en la lírica arcaica y la tragedia griega", EMFRITA 51, 1983, pp.65-68.

II. VII 157. Con razón para este pasaje escribe Vernant, "La belle mort...", p. 57: «Hêbê désigne moins, dans ce contexte, une classe d'âge précisément définie, que cette période de la vie où l'on se sent en état de se surpasser, où le succès, la réussite, le $k y d o s$, semblent attachés à vos pas, associés à vos entreprises, plus prosaïquement, où l'on est en pleine possession de ses forces". 
dar alusiones, trazos relativos a los menores de edad; material que, en debida combinación, permite lograr lo que podriamos denominar retrato homérico del niño y del muchacho, o idea homérica de lo que son las más jóvenes edades de la vida del hombre.

Cuando Homero, por la boca de Fénix, califica la infancia de á $\lambda \varepsilon$ $\gamma \varepsilon ı v \dot{\text {, molesta }}{ }^{23}, \mathrm{y}$ alude a los esfuerzos y penalidades que los niños exigen de los adultos ${ }^{24}$, no está echando mano de un tópico vacío. Lo que hace es presentar en una ocasión conveniente el aspecto negativo inherente a la niñez; Fénix quiere destacar ante Aquiles su cariño y paciencia de ayo para lograr puntos de ascendiente en la misión que le lleva ante el hijo de Peleo. Parcializa, pero no exagera. Además, no sólo el pequeñin por quien hay que hacer todo, sino el niño en general tiene. debido a su natural inmadurez, negatividades evidentes y universalmente reconocidas. En ocasiones el poeta las utiliza en referencia peyorativa a personas mayores a las que se pretende criticar o incluso insultar. Asi, Menelao increpa a Etoneo diciéndole que hace gala de simplezas de niño ${ }^{25}$ y Atenea dice a Telémaco que se deje de infantilismos que ya no le van ${ }^{26}$. Ese infantilismo puede ser, por ejemplo, inconsciencia irresponsable, como la que llevó a la muerte a Polidoro (vฤாı́́n, dice el texto homérico) ${ }^{27}$; puede ser incontinencia de palabras, cual leemos en algún otro pasaje ${ }^{2 x}$; puede ser puro y simple miedo, como se desprende de los lugares en que hay alusión al temor infantil impropio de guerre$\operatorname{ros}^{29}$. El niño se caracteriza también por su incapacidad para distinguir entre el bien y el mal. En un pasaje odiseico dice Telémaco a su madre que ya está en condiciones de discernir y comprender las cosas, buenas y malas, mientras que anteriormente no había sido otra cosa que un niño ${ }^{30}$ : y Odiseo, en otra ocasión, dice del propio Telémaco que ya es capaz de entender lo que pasa en palacio, pues ha dejado de ser un

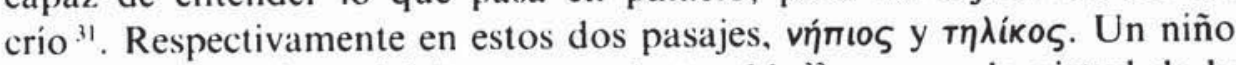
que piensa con buen juicio es cosa destacable ${ }^{32}$, porque la virtud de la

\footnotetext{
"Por boca de Fénix, quien recuerda la niñez de Aquiles: Il. IX 491.

$24 \quad$ II. IX 492.

25 Od. IV 32. Véase I. M. Hohendahl-Zoetelief, Manners in the Homeric Epic, Leiden 1980 , pp. 45-48.

:6 Od. I 296-297.

27 II. XX 411. Véase J. Griffin, Homer on Life and Death, Oxford 1980, p. 126.

$2 k$ II. XX 211-212. Insistencia en XX 244.

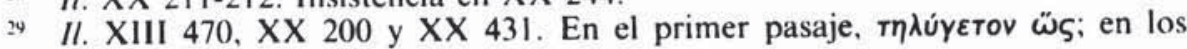
otros dos, vทnútiov ш̈s.

30 Od. XVIII 228-229. Virtualmente igual en XX 309-310.

$3 \quad O d$. XIX 85-88. Véase fórmula paralela en $O d .1297$.

32 Od. XVIII 216.
} 
sensatez no le es propia, como no lo es ni siquiera de los jóvenes ${ }^{33}$. Dice Odiseo de Nausícaa que, cuando el encuentro de ambos en la playa, hizo gala de buen criterio a su respecto, contra lo esperable de los jóvenes, que tienden a la insensatez. Néstor dice en una ocasión de Diomedes que ha hablado cual corresponde, discretamente, y ello a pesar de ser joven ${ }^{34}$. Pues, como dice el poeta en otro lugar, los pocos años se caracterizan por la mente rápida, pero el discernimiento escaso ${ }^{35}$. Sin duda por ello se puede decir que el pensamiento de los jóvenes es inestable, revolotea, literalmente ${ }^{36}$, y que debe imponerse siempre la opinión de los mayores ${ }^{37}$. La poca edad lleva aparejada la falta de convencimientos arraigados, de criterio, y como consecuencia es presa fácil de asechanzas y tentaciones ${ }^{38}$, así como de abusos ${ }^{39}$. Todo esto, tanto más acusado cuanto menor es el número de años, permite a Homero referencias al niño en sus carencias y en su desvalimiento. Un niño puede descontrolarse y ponerse peligrosamente violento en el juego, como le ocurrió a Patroclo, quien llegó a dar muerte a uno de sus pequeños $\operatorname{compañeros}^{40}$. Un niño es incapaz del trabajo y de la oratoria ${ }^{41}$. Un niño no tiene en su mano sino hacer cosas fáciles, cual se desprende de

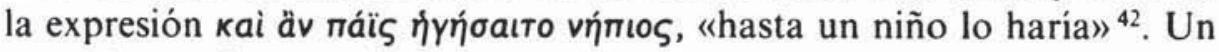
pequeño, en fin, manifiesta su debilidad e indefensión llorando y diciendo que quiere marcharse a casa, que es lo que Odiseo dice de los aqueos desanimados de continuar la acción militar contra Troya ${ }^{43}$. Pero, en notable contraste, la escasamente flexible ética social homérica no es capaz de aplicar atenuantes a un niño que contraviene las normas de actuación dejándose llevar por las limitaciones propias de la edad, aunque reconocidas ${ }^{44}$.

33 Od. VII 292-294.

14 Il. IX 57-59. Cf. Ø. Andersen, Die Diomedesgestalt in der Iliad, Oslo 1978, p. 121.

II. XXIII 590 .

II. III 108.

Il. I 258 y VIII 60-62.

Por ejemplo, Il. VII 235 y XXIV 433.

Los pretendientes de Penélope violentaban a Telémaco: $O d$. XXIII 9.

40 Il. XXIII 85-88. Sobre la dimensión jurídico-social del episodio, E. Cantarella, Norma e sanzione in Omero. Contributo alla protostoria del diritto greco. Milán 1979, pp. 267-268, y J. Roisman, "Some Social Conventions in Homeric Society», Acta Classica 25,1982 , pp. 38-39.

41 Il. IX $440-441$ y Od. IV 818

42 Od. VI 300-301.

43 Il. II 289-290. Al tratarse en este caso de una niña, a la indefensión infantil se añade aqui la tópica debilidad femenina de la que Homero da suficientes ejemplos; cf. M. Woronoff, "La femme dans l'univers épique (Iliade)", en E. Lévy (ed.), La femme dans les sociétés antiques, Estrasburgo 1983, pp. 33-34.

44 A. W. H. Adkins, Merit and Responsibility. A Study in Greek Values, Oxford 
Los poemas homéricos no dejan, en contrapartida, de sucumbir a veces, y ello como eficaz recurso, ante la fascinación de la infancia. Concretamente me quiero referir a un tema particular, que se enmarca en lo que acabo de decir y que comporta una dimensión mítico-antropológica, anterior a Homero sin duda y muy ricamente documentada después. El tema es el del héroe-niño, y en formulación más comprensiva es el de la exaltación de lo muy joven, especialmente de cara al combate. Polidoro, el más querido de los hijos de Príamo, era a un tiempo el más joven y el más rápido ${ }^{45}$; es la insinuación del tema. Néstor, siendo muy joven, venció al gigantesco Ereuterión, contra quien ninguno de los mayores se habia atrevido a presentar batalla ${ }^{46}$; $y$ aqui la excelencia de un adolescente queda ya claramente formulada en contexto guerrero. Más completo es el caso de Antíloco, que era el más ligero en la carrera, el más esforzado en el combate y, naturalmente, el más joven de los aqueos ${ }^{47}$. El escalón superior es el del héroe-niño en manifestación inverosímil y con entronque mítico más evidente. Es el caso de Oto y Efialtes, hijos de Ifimedea, de quienes dice el poeta que a los nueve años tenian una estatura gigantesca ${ }^{4 x}$ y que se atrevieron a desafiar a los dio-

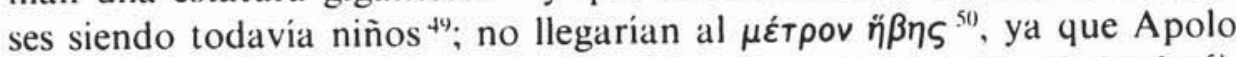
les quitó la vida antes de que les floreciera la primera pelusa de barba ${ }^{51}$. Homero conoce, y emplea a modo de fósil, estas encarnaciones extrañas de una antinatural sublimación infantil, aunque, por lo general, su exposición de hechos discurre por un claro realismo de pies en el suelo.

Nuestros poemas presentan al niño sufriendo la guerra, pero en circunstancias normales al margen de la guerra. Un hibrido entre la sublimación y el realismo es el caso de los particulares gemelos, a par o a pares, Moliones-Actoriones ${ }^{52}$. Guerreros-niños, si, aunque el poeta no

1960 , p. 53, y J. S. Lasso de la Vega, "Hombres y dioses en los poemas homéricos", en L. Gil (ed.), Introducción a Homero, Madrid 1963, p. 294.

4s II. XX 409-410.

46 II. VII $151-155$.

47 Il. XV 569-570.

48 Od. XI $311-312$. Dejemos de lado las medidas concretas, que responden a un juego voluntario con el numeral nueve.

49 Od. XI 313-314.

so $O d$. XI 317 . En 307 ya se habia dicho que su vida fue corta.

st Od. XI 319-320.

52 Il. XI 709-710. Toda la problemática relativa a estos extraños personajes no queda agotada ni resuelta en el, por lo demás, espléndido trabajo de G. Stagakis, "The stemma of the Actoriones in Homer", Studies in Homeric Society. Wiesbaden 1975 , p. 9 ss. Véase también P. A. Bernardini, "Eracle, i Molioni e Augia nell'Olimpica 10 di Pindaro", Quaderni Urbinati di Cultura Classica, N.S. 11, 1982, pp. 60-63, y $\mathrm{H}$. von Kamptz, Homerische Personennamen. Sprachwissenschaftliche und historische Klassifikation, Gotinga 1982, pp. 31, 34 y 245-246. 
deja de decir que, por serlo, no habían tenido ocasión todavía de demostrar su valor. Estos gemelos, quizá siameses ${ }^{53}$, aparecen presentados como guerreros menos hechos que los dos hijos de Ifimedea y desde luego se encuentran muy lejos de la ferocidad que Esquilo pone como

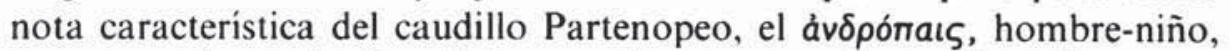
con rostro de muchacha, si damos valor a su nombre parlante ${ }^{54}$. Homero sabe que el menor no está capacitado para la guerra ${ }^{55}$; no tiene fuerza para ella, porque las heridas infligidas por los niños no llegan a causar dolor, como en una ocasión manifiesta el caudillo Diomedes ${ }^{56}$. Es más; Homero dice que los niños ni siquiera se preocupan de la guerra ${ }^{57}$. lo que pone en boca de un Néstor que compara a sus compañeros del ejército con niños pequeños. A lo más que Homero llega, sin salir de lo lógico y posible, es a presentarnos a combatientes noveles en la lucha ${ }^{58}$ y a niños y muchachos en la defensa de los muros en ocasión desesperada. Esto es lo que tenemos en una de las escenas del escudo de Aquiles, vท́mı тย́kva en este caso, y lo que dispone Héctor que se haga en Troya

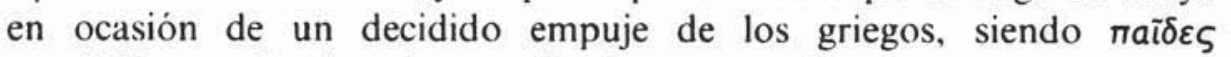
$\pi \rho \omega \vartheta \dot{\beta} \beta a \iota$, muchachos, los movilizados esta vez ${ }^{59}$.

La guerra propiamente es de los hombre jóvenes, pero maduros:

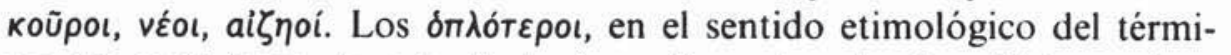
no. Es en la lanza de estos luchadores formados donde está la suerte y la esperanza de quienes por su edad no pueden combatir. La misión del

53 Véase Hesiodo, Eeas, fr. 17 a, 16-17, que parece apuntar a dos monstruos paralelos con dos cabezas, cuatro pies y sólo dos brazos. Referencias a las representaciones sobre cerámica en T.B.L. Webster, From Mycenae to Homer, Londres 1964, pp. 174-175, y L. Achillea Stella, Tradizione micenea e poesia dell Iliade, Roma 1978, p. 252.

54 Esquilo, Siete contra Tebas 533. Comentario e interpretación antropológica adecuados en L. Lupas-Z. Petre, Commentaire aux Sept contre Thèbes d'Eschyle, Bucarest-París 1981, pp. 173-174. Véase también G. O. Hutchinson, Aeschylus, Septem contra Thehas, Oxford 1985, pp. 126-127. Terribilidad asimismo del joven personaje en Euripides, Fenicias 146-147.

5s Véanse los cuadros de W. C. Scott, The Oral Nature of the Homeric Simile, Leiden 1974, p. 191 ss., con la frecuente relación doce casos - "child-unwarlike».

s6 II. XI 389-390.

57 II. II 337-338.

5x Además del ya citado caso de los Moliones-Actoriones, que murieron sin poder demostrar su valor, podriamos mencionar a Simoisio también prematuramente muerto por Ayante Telamonio en II. IV 474 ss. Este joven personaje era $\eta \hat{i} \vartheta \varepsilon o s$ y aparece comparado por el poeta con un álamo talado, liso y con ramas arriba. Ya de por sí el término $\eta \hat{\imath} \vartheta \varepsilon \circ \zeta$ comporta muy marcada juventud; pero además podria ser que tuviera razón S. L. Schein, The Mortal Hero, Berkeley-Los Angeles-Londres 1984 , p. 75 , al afirmar que el poeta sugiere con la imagen la adolescencia, casi infancia, del combatiente caido; lampiño todo su cuerpo, salvo el cabello de la cabeza.

${ }^{59}$ Respectivamente Il. XVIII 514-515 (véase Wickert-Micknat, Die Frau, pp. 89) e II. VIII 517-519. 
guerrero en los poemas homéricos tiene como elementos esenciales la defensa de la ciudad, de las esposas, de los ancianos y, sobre todo, de los hijos en tierna edad ${ }^{60}$. Es la patria y los débiles de retaguardia lo que en su suerte depende del esfuerzo y éxito de los combatientes ${ }^{61}$. Tanto el tema de los niños sitiados en Troya como de los que esperan lejos en retaguardia aparece con frecuencia en la Ilíada. El segundo de los casos se da por lo general cuando un caudillo rememora lo que dejó en su patria lejana. Agamenón recuerda a los hijos de los griegos que esperan en palacio ${ }^{62}$; Sarpedón, al suyo propio, que quedó en la tierra de Licia ${ }^{63}$. Si el guerrero muere lejos del hogar, su hijo no volverá a verlo, y hasta puede que acabe por olvidarlo del todo, como dice Diomedes que le ocurrió siendo niño, tUтЯós, con su padre Tideo, cuando éste sucumbió ante los muros de Tebas ${ }^{64}$. El recuerdo de los hijos distantes anima al combatiente y Néstor utiliza el recurso con eficacia en una de sus arengas ${ }^{65}$. A Homero no se le escapa el detalle de que la preocupación por los niños, y también por las mujeres, ha de ser necesariamente mayor en quienes los tienen cerca y los defienden de manera directa que en aquellos en los que esta circunstancia no se da. Aunque los aliados de Priamo están, como recuerda Héctor, para defender a las esposas e hijos (vímıa те́кva) de los troyanos ante el acoso de los griegos $^{66}$, es natural que su esfuerzo no iguale al de los propios guerreros de Ilión. Hay un pasaje iliádico en que se nos dice que, mientras los aliados duermen, los troyanos velan, porque aquéllos no tienen cerca ni a sus mujeres ni a sus hijos y éstos $\operatorname{si}^{67}$. No extraña, pues, que el tema del niño en el contexto de la misión del guerrero surja con cierta reiteración cuando se habla del lado troyano y no en relación con el ejército griego, sitiador y desplazado.

Algo de lo dicho anteriormente, y ello es fácilmente comprensible, adquiere no poca funcionalidad en relación con el esforzado caudillo

^) Véase M. Scott, «Pity and Pathos in Homer», Acta Classica 22, 1979, pp. 3-4, y también, destacando la significación de la esposa en este contexto sobre la de los hijos, K. Hirvonen, Matriarchal Survivals and Certain Trends in Homer's Female Characters, Helsinki 1968, pp. 104-105.

of La derrota les depara triste final. Ver M. F. Fittipaldi, The Fall of the City of Troy and its Significance in Greek Poetry from Homer to Euripides, diss. Yale University 1979, p. 29. Sobre el tema en general, E. Vermeule, Aspects of Death in Early Greek Art and Poetry. Berkeley-Los Angeles-Londres 1979, pp. 112-116.

62 Il. II 136-137.

6.) II. V 480-481.

64 II. VI 222-223.

os Il. XV 662-663.

of Il. XVII 223-224.

67 II. X 419-422. 
troyano Héctor. Como ya he destacado en otro lugar ${ }^{68}$, él es quien lleva el peso y la responsabilidad de la resistencia de los asediados. Troya depende de su príncipe e incluso el poema se atreve a sugerir que la esperanza de la ciudad coincide con la vida de su p.aladín ${ }^{69}$. Uno de los más famosos episodios de la Iliada es el de la despedida de Héctor y Andrómaca, donde se entrama vivencia de miedo a lo posible y premonición de un destino inexorable ${ }^{70}$, lo que tiene sus contrapuntos en el antepenúltimo y último de los cantos del poema, muerto ya el hijo de Príamo ${ }^{71}$. Se abre la escena del adiós con unas palabras de Héctor en las que, junto a la intención de despedirse de su mujer e hijo, deja caer el sombrío presentimiento de que lo más fácil es que no regrese ${ }^{72}$. Destaco sobre todo ese pronombre $\sigma \phi i v$, que convierte la vuelta del combatiente en algo particular y vital para los suyos. Héctor no sabe si les volverá; a ellos, su mujer y su hijo. Andrómaca, que también teme lo peor, echa en cara al guerrero su despreocupación por el pequeño y por ella misma. La mujer invierte la escala de valores de su esposo: supedita el bien común de la ciudad al bien propio familiar ${ }^{73}$. Pero para Héctor, como para cualquier griego, la patria está por encima de los hijos o, mejor, no hay contradicción de intereses porque los generales y los particulares son los mismos. Patria y familia penden del honor responsable del guerrero, la al $\delta \omega^{\prime} \varsigma^{74}$, y no cabe dar por salvos a los débiles propios, si el combatiente, en reacción egoísta, evade sus primordiales obligaciones militares. Para Homero, sin embargo, es fundamental que el guerrero viva. Ya casi al final del poema, la muerte de Héctor, de quien Andró-

68 Véase L. García Iglesias, "Patria y misión del guerrero en la antigua Grecia», en A. del Castillo (ed.), Ejército y sociedad. Cinco estudios sobre el Mundo Antiguo, León 1986, p. 95. En particular sobre el caudillo troyano, la más atractiva figura del poema, S. Farron, "The Character of Hector in the Iliad", Acta Classica 21, 1978, p. 39 ss.

69 Il. XII 10-11. A. Thornton, Homer's Iliad: its Composition and the Motif of Supplication, Gotinga 1984, pp. 61, 70-72 y 86, advierte que el poeta llega a utilizar la eventual, probable, muerte de Héctor como un signo ominoso, "foreshadowing".

70 La plegaria de despedida de Héctor, con su pequeño en los brazos, comporta una nota de optimismo que, sin embargo, da por supuesta la propia inminente muerte del caudillo troyano. Farron, "The Character of Hector...", p. 42, califica esta plegaria de «incongruous", lo que no tengo por ajustado. Aunque se tema y asuma lo peor, no es incongruente pedir a los dioses lo mejor.

"Woronoff, "La femme...", pp. 40-41.

II. VI 365-367.

II. VI 407-409 y 431-432. Véase L. Garcia Iglesias, "La mujer y la polis griega", en E. Garrido (ed.), La mujer en el Mundo Antiguo, Madrid 1986, p. 118.

74 Sobre la al $\delta \dot{\omega}$, realmente vergüenza de no hacer lo que se debe o de fracasar en lo que se hace, Adkins, Merit and Responsibility, pp. 43-46; J. M. Redfield, Nature and Culture in the "Iliad", Chicago-Londres 1975, p. 113 ss., y Schein, The Mortal Hero, pp. 177-179. 
maca dice que era el defensor de mujeres y niños, deja sin futuro al pequeño Astianacte ${ }^{75}$; morirá sin duda en venganza de quienes perecieron a manos de su padre ${ }^{76}$; muchos, pues Homero aplica a Héctor el califi-

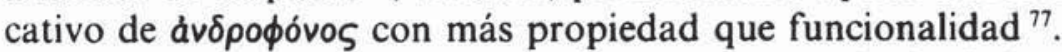

La desdicha que aguarda a Astianacte es resultado de la conjunción de dos elementos: el de la venganza en el hijo y el de la indefensión y el desamparo del huérfano en menor edad, tema este último que Homero trata con patetismo no exento de ternura en un puñado de versos del canto XXII, referidos precisamente al hijo de Héctor y puestos en boca de su madre Andrómaca ${ }^{78}$. El día de su orfandad deja al niño sin amigos, cabizbajo y lloroso; su necesidad le lleva a acudir a los compañeros de su padre y a tirarles de la ropa, y sólo alguno se compadecerá y le ofrecerá un pequeño vaso que no llegue a más que humedecer los labios. El niño cuyo padre vive expulsará al huérfano del banquete, golpeándole e insultándole...; un huérfano que ya es Astianacte, porque, si el pasaje comienza con un cierto tono de generalidad, va luego personalizándose, hasta mencionarlo, en el infortunado hijo de Héctor ${ }^{79}$. La desgracia del hijo - Homero lo deja caer en bastantes ocasiones- es consubstancial a la muerte del guerrero ${ }^{80}$.

Es lugar común en los poemas la alusión a la esclavitud de las mujeres e hijos del vencido. Lo que se tiene por normal es que el vencedor dé muerte a los varones y reduzca a la esclavitud a mujeres y a niños ${ }^{81}$. Es lo que dice Meleagro que hacen quienes conquistan una ciudad ene-

75 Il. XXIV 726-730.

76 II. XXIV 734-738. Véase Ch. Segal, The Theme of the Mutilation of the Corpse in the Iliad, Leiden 1971, p. 69, y Cantarella, Norma e sanzione..., p. 231. Sobre la muerte de Astianacte, arrojado desde una torre, cual adelanta Andrómaca (Il. XXIV 734-735), véase F. Johansen, The Iliad in Early Greek Art, Copenhague 1967, pp. 2831; Stella, Tradizione micenea..., figs. 55 y 58; Fittipaldi, The Fall of the City of Troy..., pp. 67, 91 y 162-163; Vermeule, Aspects of Death..., pp. 114-115; R. Aélion, Euripide héritier d'Eschyle, I, Paris 1983, p. 322, y en espléndido tratamiento reciente, H. Rühfel, Das Kind in der griechischen Kunst, Maguncia 1984, pp. 45-59.

7 W. Whallon, "Is Hector androphonos?", Arktouros. Hellenic Studies presented to Bernard M. W. Knox. Berlin-Nueva York 1979, pp. 19 ss., especialmente 22-24.

${ }_{78}$ Il. XXII 490-500.

79 S. Farron, "The Portrayal of Women in the Iliad", Acta Classica 22, 1979, p. 25, resume el espíritu de Andrómaca en este parlamento sobre la creencia de que "the father is the only parent who can guarantee a child's social acceptance".

${ }_{80}$ Aparece incluso en la euforia de quien vence. Asi en Il. XI 394. Llama la atención, por lo que tiene de rasgo moderno, que Héctor arengue a sus tropas en II. XV 496-497, diciendo que será motivo de honra morir por la patria, lo que tendrá

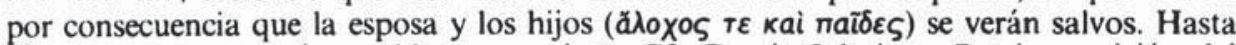
Tirteo no se recreará una idea como ésta. Cf. García Iglesias, «Patria y misión del guerrero...", p. 96.

${ }^{81} \quad$ Véase Redfield, Nature and Culture..., pp. 120-121. 
miga ${ }^{{ }_{2}}$. Es lo que teme Príamo para los suyos, con la variante de una alusión expresa a mal trato de los niños, arrojados por el suelo ${ }^{83}$. Es lo que hacen los compañeros de Odiseo en la historia ficticia de actividades piráticas en Egipto ${ }^{84}$, que a la postre la piratería no era sino una modalidad de guerra que no escatimaba gloria al exitoso. El rapto de niños era cosa frecuente de cara a satisfacer los mercados de esclavos ${ }^{85}$.

Pasando a otra cuestión, los poemas homéricos tienen el tema de la crianza del niño, o la que se recibió de niño, como uno de los más recu-

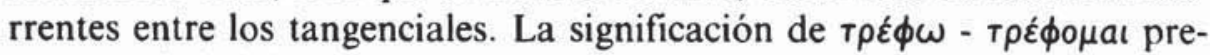
senta variedad de sentidos en variedad de $\operatorname{contextos}^{86}$. En ocasiones este sentido es general e impreciso; asi cuando hay alusión al puro y simple paso de la niñez en palacio ${ }^{87}$, o a la vida en abundancia de un pequeño principe, concretamente Orestes ${ }^{8 x}$, o a las atenciones con que se reviste la inserción de un niño dentro de una familia ${ }^{89}$. En una ocasión dice Tetis, en bella imagen, que crió a su hijo Aquiles como se hace con una planta en lugar apropiado ${ }^{\%(}$ y que, en consecuencia, el muchacho pujó cual lo hace un retoño hasta destacar entre los héroes ${ }^{91}$. Muy velada y poéticamente tenemos aquí una relación entre la crianza y lo que se será de mayor. Homero, indudablemente, concatenaba el hecho material de sacar adelante a los niños con cierta suerte de educación; cosa evidente, por ejemplo, en el verso en que el protagonista de la Odisea

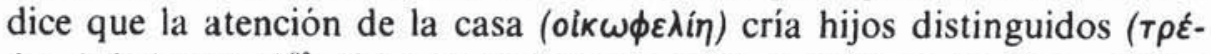

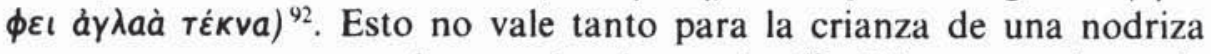
o una aya, como para la que dan los padres ${ }^{93}$; diferente carácter de crianza que Homero sabe distinguir. Porque, si es cierto que el poema

82 II. IX 593-594.

33 Il. XXII 63-64.

*4 Od. XIV 264, en relato de Eumeo, y XVII 433, en relato de Antínoo.

"s Od. XV 415 ss.; L. Gil, "El individuo y su marco social», en L. Gil (ed.), Introducción a Homero, Madrid 1963, p. 373.

${ }_{86}$ Véase estudio pormenorizado, que en muchas consideraciones lingüisticas nos

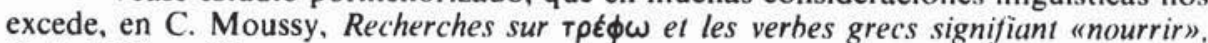
Paris 1969, p. 33 ss.

87 Asi en $\mathrm{Od}$. XIV 201.

ks II. IX 142-143 y 284-285, ambos pasajes idénticos, salvo en una persona verbal.

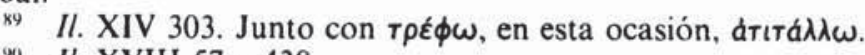

9) Il. XVIII 57 y 438.

y1 Il. XVIII 55-56. El tema reaparece en $O d$. XIV 174-177, referido esta vez a Telémaco. Véase C. Moulton, Similes in the Homeric Poems, Gotinga 1977, p. 143.

92 Od. XIV 223.

93. Nodriza o aya, porque трофós no se refiere invariablemente a la mujer que amamanta a un niño ajeno, como $\tau \rho \varepsilon \hat{\phi} \omega$ no significa amamantar; cf. Wickert-Micknat, Die Frau, p. 70. 
utiliza en ocasiones fórmulas idénticas para la crianza paterna y para la

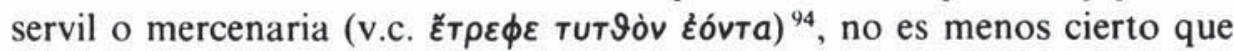
hay contextos homéricos que sugieren una dimensión más profunda en la atención de los niños por sus padres naturales. Es más; para Homero es normal la diferencia de trato entre los hijos propios y los que no lo son. Por ejemplo, cuando se refiere a la niñez de Eudoro, hijo de soltera, en casa de Filante ${ }^{95}$ o a la de Pedeo, criado por Téano sin ser su hijo ${ }^{96}$, y en ambos casos insiste el poeta en que recibieron trato como hijos propios ${ }^{97}$, está revelando claramente ese matiz de mayor profundidad que atribuye a la crianza según carne. Las excepciones, como estas dos, merecen que se las resalte, y el poeta asi lo hace.

No es a propósito de Pedeo, el bastardo de Antenor, la única vez que los poemas aluden, como cosa notable, a la crianza de un bastardo como si de un hijo legítimo se tratara. Agamenón, dirigiéndose a Teucro, le recuerda que Telamón le crió siendo niño y le cuidó en su casa pese a su condición de bastardo ${ }^{98}$, y Odiseo, en su autobiografia ficticia, dice ser hijo de una concubina, pero bien tratado por su familia, sin diferencias respecto a los hijos legitimos ${ }^{99}$. Esta equiparación de trato entre el bastardo y los hijos legítimos, que nuestros poemas destacan ${ }^{100}$, se complementa con la no infrecuente alusión al acogimiento de niños que no son hijos de ninguno de los dos cónyuges, se trate de un miembro de la familia, caso de Ifidamante, que fue criado por su abuelo materno $^{101}$, se trate de un extraño, caso de Patroclo criado por Peleo ${ }^{102}$, de

${ }^{94}$ Il. XXII 480 y $O d$. XI 67 , en referencia a crianza de padres, y $O d$. I 435 , tratándose de crianza servil

95 Il. XVI 191-192.

\% Il. V 70-71. Cf. Hirvonen, Matriarchal Survivals..., p. 111. Pedeo era un vółos de Antenor, el esposo de Téano. Lo especial es el trato que la mujer dio al bastardo del marido, y no que el bastardo viviera en casa del padre natural, porque esto era lo usual en derecho homérico. Véase Cantarella, Norma e sanzione..., p. 176, y Wickert-Micknat, Die Frau, pp. 84-86. Sobre la situación de los bastardos en Homero, en función de los distintos niveles de unión, desde el matrimonio al concubinato, ver M. Weinsanto, "L'évolution du mariage de l'Iliade à l'Odyssée», en E. Lévy (ed.), La femme dans les societés antiques, Estrasburgo 1983, pp. 49-51.

${ }_{97}$ No es igualmente válido el caso de Imbrio, considerado por Príamo como uno más entre sus hijos (II. XIII 176), porque su integración en la casa real troyana no ocurrió en la infancia, como en los dos casos anteriores, sino por vía de matrimonio.

98 Il. VIII 283-284.

99 Od. XIV 202-204. Véase Hirvonen, Matriarchal Survivals..., p. 185.

100 Sobre ello Hirvonen, Matriarchal Survivals..., pp. 22-23 y 41, nota 3.

101 Il. XI 223-224.

102 Il. XXIII 84 y $89-90$. Se puede considerar la dislocación de Patroclo, aun siendo niño, como un exilio por homicidio, cual en el simil de Il. XXIV 480-484. Cf. Moulton, Similes..., pp. 114-116, y Cantarella, Norma e sanzione..., pp. 234-238. 
Eumeo criado por Laertes ${ }^{103}$ y de Melanto criada por Penélope ${ }^{104}$. En

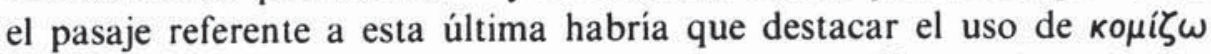
y árı́á $\lambda \lambda \omega$, indicativos de una especial dedicación ${ }^{105}$, y la introdución del tema del desagradecimiento de la pupila para con quien tan buen trato le habia brindado ${ }^{106}$. Es evidente que en la mentalidad homérica la crianza exigia una contrapartida futura por parte del beneficiario de ella. Compensación agradecida que Melanto escatima a Penélope; compensación a la que Deifobo anima a Eneas, incitándole a combatir por el cadáver de Alcátoo, el cuñado que le crió de niño ${ }^{107}$; compensación, pago incluso, que se espera hasta de los hijos propios. Simoisio e Hipótoo, muertos ambos por Ayante Telamonio, no llegaron a pagar a sus padres la crianza por haber sucumbido muy jóvenes, utilizándose en los pasajes relativos a uno y otro exactamente la misma fórmula: oú $\dot{\varepsilon}$ ro-

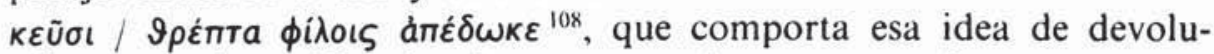
ción necesaria y obligada, al menos moralmente, y por lo tanto esperable salvo desaparición prematura del hijo, cual en los casos citados.

Homero, que presenta líneas de conducta diversas con las que no siempre está de acuerdo, aparenta a veces inconsecuencias de principio que, bien miradas, no llegan a ser tales. La benevolencia de Téano con Pedeo, antes aludida, contrasta vivamente con las reservas de nuestro poeta respecto a la conveniencia de dar padrastro a un hijo huérfano.

103 Od. XV 363-365. Eumeo no se crió como un hermano de Odiseo, sino junto con Ctimene, hija menor de Laertes y Anticlea, por lo que es buena la conclusión de que el porquerizo prohijado era más joven, contra la idea general, que el caudillo de los mil ardides, como establece J. H. Finley, Homer's Odyssey, Cambridge Mass.Londres 1978, p. 49.

104 Od. XVIII 322-324.

105 Este último verbo podria tener etimológicamente relación con la paternidad

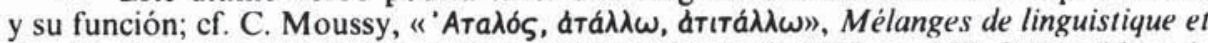
de philologie grecques offerts à Pierre Chantraine, Paris 1972, p. 157. Su sentido originario puede ser el que refleja el cuidado de los hijos por sus padres, pero también se utiliza respecto a personas que sustituyen a los padres en las atenciones que requiere un niño; cf. Moussy, l.c., pp. 161-162. Cuando se emplea más de un verbo de sentido afin, es drıtád $\lambda \omega$ el que expresa la idea de solicitud. No lo entiende asi, a mi parecer equivocadamente, H. W. Nordheider, en B. Snell-H. Erbse (edd.), Lexikon des frühgriechischen Epos, cols. 1500-1501. Tampoco está fundamentada la explicación institucional de E. Benveniste, Le vocabulaire des institutions indo-européennes,

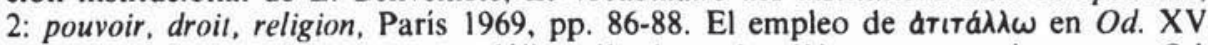

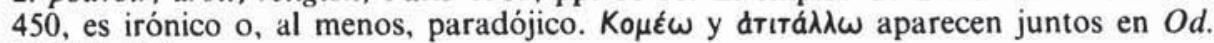
XI 249-250.

106 Extraña no encontrar este pasaje en el capítulo "Gratitude» de HohendahlZoetelief, Manners in the Homeric..., p. 109 ss.

107 Il. XIII $465-466$.

108 Il. IV $477-478$ y XVII 301-302. Según Griffin, Homer on Life..., p. 108, el tema de los «bereaved parents» lo utiliza el poeta como uno más de los efectos patéticos. 
Realmente no hay contradicción. Ni Homero piensa que absolutamente todos los padrastros son malos ni, menos - sabe demasiado de la vida -, que todos son buenos. Los poemas homéricos inician, pues, pese a alguna que otra notable excepción, el aprovechamiento del tópico de vida que es la casi siempre negativa experiencia de un padrastro o una madrastra para niños sin padre o sin madre. Odiseo, al partir, pidió a Penélope que esperara a casarse de nuevo hasta que a Telémaco le asomara la barba ${ }^{109}$, y en otro pasaje es el propio joven príncipe quien se niega a las nuevas nupcias de su madre ${ }^{110}$. Para ser más exacto, era el Telémaco niño quien se negaba a ello. Es claro, problemas de herencia y de inserción familiar aparte, que para Homero las segundas nupcias comportaban un riesgo que las hacía desaconsejables. Hay un pasaje, odiseico como los anteriores, que enfoca explícitamente la cuestión hacia el desamparo de los hijos de un primer matrimonio desde que se contrae el segundo. No sólo el padre por vía de matrimonio, sino el propio progenitor natural acaba despreocupándose de los pequeños ${ }^{\prime \prime \prime}$.

Aunque nuestros poemas sugieran que una madre que ha contraido nuevo matrimonio puede desentenderse de los hijos del primer esposo, algo que ni a niveles teóricos podría resultar admisible como regla general en otros contextos culturales y sociales, es muy reiterativo a la hora de referirse al principio de que los padres quieren a sus hijos y se esfuerzan por ellos y su bienestar. Para el mundo animal lo testimonia con repetidos, bellos y hasta patéticos ejemplos: las avispas defendiendo encorajinadamente sus hijitos ${ }^{112}$, la vaca con su ternerillo recién nacido ${ }^{113}$, los pájaros que ven sus crías amenazadas por el gavilán ${ }^{114}$, el león vigilando a sus cachorros ${ }^{115}$, las yeguas orgullosas de sus jóvenes potros... ${ }^{116}$ En los hombres, dentro de una mayor complicación de dimensiones, igual. Cuando Telémaco quiere ejemplificar con una benevolencia tipo no acude a otra referencia que a la del padre respecto a

109 Od. XVIII 269-270. Como dice Eurínome en $O d$. XVIII 175-176, Penélope pedia a los inmortales conocer el nacimiento de la barba en las mejillas de su hijo. En el momento en que se desarrolla la acción del poema, Télemaco ha dejado ya o está dejando ya de ser barbilampiño; cf. el pasaje odiseico citado y Finley, Homer's Odyssey, p. 182.

110 Od. XIX 530-532. Véase S. P. Scully, "The Bard as the Custodian of Homeric Society", Quaderni Urbinati di Cultura Classica, N.S. 8, 1981, pp. 70-71.

III Od. XV 20-23.

112 Il. XII 167-170 y XVI 264-265.

113 Il. XVII 4-6.

114 Il. XVII 755-757.

115 Il. XVII 133-136.

116 Il. XX 221-222. 
los hijos ${ }^{117}$. De un padre se puede decir que pasa penalidades por el hijo bien amado 118 ; a una madre se la puede presentar en sus fatigas diarias de trabajadora para llevar a casa corta soldada con que alimentar a sus hijos ${ }^{119}$; y, cuando se superpone otro amor al filial, cual hace Aquiles con el de Patroclo frente al de Neoptólemo, es menos lo que se rebaja el cariño del hijo que lo que se ensalza ponderativamente el amor del amigo mediante la extremada comparación ${ }^{120}$. Si hay una benevolencia que pueda ser proverbial es la del padre, y con ella queda comparada la dulzura que Odiseo derrocha en el gobierno de su pueblo ${ }^{121}$.

El trato de los hijos y lo que suponen de carga durante su niñez recibe amplio tratamiento en los poemas homéricos a través de una nutrida colección de escenas de vida familiar que van del tópico a la ternura y de la ternura a lo que son particularidades culturales concretas. Tenemos alusión a la madre que amamanta a su hijo pequeño ${ }^{122}$, y junto a tan natural escena, las sin duda tiernas de la madre que espanta una mosca de su hijo dormido ${ }^{123}$, del niño que busca refugio en su madre o en una sirvienta ${ }^{124}$, y de la niña que llora y tira del vestido de su madre para que la aúpe ${ }^{125}$. Se trata de acciones y reacciones instintivas, naturales; consubstanciales casi con la humanidad. Como también lo son la sonrisa del padre o de los padres sobre el hijo común ${ }^{126}$ y el sentimiento de espanto, de extrañeza, por parte de un niño cuando ve a su padre de una guisa a la que no está acostumbrado ${ }^{127}$.

Hay pasajes en Homero referentes a lo que el padre supone de dicha para sus pequeños cuando éstos pueden contar con él y no se ven privados de su protección, presencia y trato por enfermedad, por guerra o por largo viaje. Un símil de la Odisea destaca la alegría de los hijos cuando el padre, enfermo, acaba por curar ${ }^{128}$. Otro pasaje, ahora iliádi-

\footnotetext{
117 Od. I 307-308. Véase Moulton, Similes..., pp. 141-142.

118 Od. XVI 17-19.

119 Il. XII 433-435.

120 Il. XIX 326-327.

121 Od. II 47, II 234 y V 12: пarì

y 142, y J. de Romilly, La douceur dans la pensée grecque, París 1979, pp. 16-17.

122 Od. XI 448-449.

123. II. IV 130-131.

124 II. VIII 271 y VI $467-468$, respectivamente.

125 Il. XVI 7-10. Cf. Scott, The Oral Nature..., pp. 73-74, en lo cierto al considerar el simil que recoge esta escena como la más famosa de las comparaciones homéricas referidas a los niños.

126 II. VI 404 y 471.

127 II. VI 467-469.

12. Od. V 394-397. Moulton, Similes..., p. 128, destaca la repetición de áráaı en el pasaje y la aparición de domaorós en el verso 398.
} 
co, presenta cómo reciben los niños al padre que regresa de la guerra: llamándole papá (el verbo паппá $\omega$ ) y abrazando sus rodillas ${ }^{129}$. Un tercer caso es el que vemos en boca de Circe: a quien, desprevenido, se acerque a las sirenas y oiga su voz, ni su esposa ni sus hijos pequeños le rodearán locos de alegría cuando vuelva al hogar ${ }^{130}$. Da la impresión de que para Homero el padre no es el educador rígido de sus hijos todavía niños, aquel a quien se respeta y teme, frente a la ternura y flexibilidad de la madre. No. La figura del padre aparece en los poemas homéricos tan capaz no sólo de querer, sino de demostrarlo con mimo y desvelo, como la madre, y - ya lo hemos visto - de provocar correspondencia en los hijos. Recordaria ahora la demostración de ternura por parte de Héctor hacia su hijo Astianacte, lo que me permite destacar el hecho de que para Homero el hijo es obra a un tiempo de madre y padre, cosa que se dice precisamente del pequeño vástago del caudillo troyano ${ }^{131}$. Recordaría escenas como las de los padres contando a sus hijos, niños, viejas historias ${ }^{132}$; o sentando a los pequeños sobre las rodillas y dándoles de comer ${ }^{133}$; o consolándoles en el regazo, como hace con Ártemis su padre Zeus en un rasgo infantil y mimoso, tanto más propio cuanto, al llamarla el poeta кoúp $\eta$, excluido el sentido de hija, parece que insiste en la juventud muy marcada de la diosa ${ }^{134}$. Los padres se hacen acompañar por los hijos para ponerles en contacto con la naturaleza y enseñarles sus secretos, como hizo Laertes con Odiseo niño, a quien iba mostrando los diferentes árboles y dándoles nombre uno a uno ${ }^{135}$. Son algunos ejemplos.

El gesto que hemos visto de sentar a un niño sobre las rodillas, indiscutiblemente cariñoso ${ }^{136}$, se repite en los poemas homéricos varias veces, incluso con el también aludido complemento de darle de comer en esa postura. Y no sólo en relación con los padres. Odiseo acostumbraba a sentar sobre sus rodillas y dar de comer a Eurimaco, que no era su hijo ${ }^{137}$. Eso mismo hacía Fénix con Aquiles durante la enojo- 
sa -que decía él- infancia de éste ${ }^{138}$. También de Fénix se dice que fue maldito por su padre para que no pudiera darle un nieto que se sentara sobre sus rodillas ${ }^{139}$, lo que contrasta con el deseo de Autólico de tener un nieto, que al final logra y le ponen sobre el regazo ${ }^{140}$. Y de este episodio referente a Autólico tiene interés un elemento nuevo, indicativo del carácter patriarcal de que goza el abuelo, algo que cuadra con la sociedad de los gene: es él el que da nombre al pequeño recién nacido. Respecto a la dieta de los niños en estas escenas, no es otra que carne y vino. Carne troceada y vino es lo que daba de comer Fénix a Aquiles ${ }^{141}$; tuétano y gordura de ovino es lo que comía Astianacte en las rodillas de su padre ${ }^{142}$; carne asada y vino es lo que Eurímaco recibía de Odiseo ${ }^{143}$. En otro lugar se habla de crianza con queso, miel y vino, que es lo que daba Afrodita a los hijos de Pandáreo ${ }^{144}$. Evidentemente, ésta es la comida propia de un niño ${ }^{145}$, mientras que lo impropio para Homero es, por ejemplo, lo dicho del hombre dañino y cruel: que fue alimentado de bilis en su niñez ${ }^{146}$.

Homero no olvida que la infancia, desvalida de por sí, requiere esas atenciones que los mayores prodigan y que globalmente caben en el amplio concepto de crianza. Esta responsabilidad no sólo recae sobre los padres, sino, como ya hemos visto, sobre otros familiares y sobre el servicio de la casa cuando lo hay. El cuidado de un niño por un servidor de la familia es cosa normal y, también normalmente, comporta una correspondecia afectiva que puede verse alguna vez materializada o que al menos se manifiesta por signos ${ }^{147}$. Telémaco decide salvar al heraldo Medonte porque siempre le atendió en palacio cuando él era un niño. Eumeo, por su parte, viejo porquerizo de la familia, otrora bien considerado, se dirige a Telémaco - un Telémaco que supera la veintenallamándole naĩs, expresión tierna de cariño por el hijo del amo deriva-

138 Il. IX 487-491.

139 Il. IX 454-456. Maldición o, tomándolo como eufemismo, castración; cf. Hirvonen, Matriarchal Survivals..., p. 25.

140 Od. XIX 399-404.

141 Il. IX 488-489.

142 Il. XXII 500-501.

143 Od. XVI $442-444$

144 Od. XX 69.

145 Incluso el vino, bebida de que no se privaban tampoco las mujeres, incluso muy jóvenes, cual Nausicaa y compañeras en $\mathrm{Od}$. VI 77; cf. Wickert-Micknat, Die Frau, p. 55, con referencias homéricas. Sobre la dieta en los poemas véase Gil, «El individuo y su marco...", pp. 439-441, y A. Albarracin, Homero y la medicina, Madrid 1970, pp. 110-114.

146 Il. XVI 203-204.

147 Excepción expresa es la de la sierva encargada de la crianza de Eumeo, quien lo vendió a unos fenicios: $O d$. XV 450-453. 
do de continuado trato ${ }^{148}$. El caso de Telémaco es especialmente significativo. Privado de padre por larga ausencia, ha tenido que crecer, educarse y hacerse hombre con los pobres sustitutivos de su madre y la servidumbre fiel. El principe de palacio, en minoría de edad, no tiene ni aun en ausencia del padre ninguna responsabilidad. Euriclea dice a Odiseo que, por ser joven Telémaco, su madre no le había dejado mando sobre las criadas de la familia ${ }^{149}$; y es que, como el propio Telémaco reconoce, el menor no está en condiciones de llevar las riendas de la casa. En su interpelación a Antínoo el joven príncipe acusa a los pretendientes de haber consumido su patrimonio mientras él era niño, vímıs. Ahora ya es mayor, $\mu \dot{\varepsilon} \gamma a \varsigma$, y el $\mu \varepsilon ́ \gamma a \varsigma$ oye, piensa y está capacitado para preocuparse por lo que es suyo ${ }^{150}$.

Voy a pasar ahora al niño homérico al aire libre, en sus entretenimientos y en su trabajo. En una ocasión vemos al niño correteando de puertas afuera de palacio ${ }^{151}$; en otra, un bonito símil, tenemos a un niño entretenido en hacer construcciones con la arena de la playa para acabar destruyendo lo hecho, con manos y pies ${ }^{152}$; otro símil presenta la imagen de un grupo de niños dedicados a hostigar a las avispas del camino, según es costumbre en ellos ${ }^{153}$. De juguetes, casi nada; sólo los astrágalos y la pelota ${ }^{154}$. Se impone la interpretación laboral en el pasa-

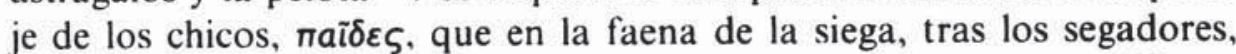
ataban los haces y los portaban entre sus brazos sin darse tregua ${ }^{155}$. Ardor en el trabajo aquí. Responsabilidad, en el cometido que desde edad muy temprana se adjudicó al vaquero Filecio; como él mismo dice, Odiseo le puso al frente de sus bueyes тuт९òv Éóvta, cuando todavía era un niño ${ }^{156}$. Y respecto a Eumeo, como la cosa más natural del mundo, el Odiseo de incógnito, haciéndose de nuevas, le pregunta si le raptaron cuando, siendo de niño, тuт९òs $\varepsilon \dot{w} v$, se quedó solo cuidando rebaño y vacada ${ }^{157}$.

${ }_{148} O d$. XXII $357-358$ y 470 ss.

149 Od. XXII 426-427.

150 Od. II 312-315.

151 Od. XV 450-451.

152 Il. XV 360-364. Cf. Scott, The Oral Nature.... p. 74, destacando la referencia realista, y Griffin, Homer on Life..., p. 130, ponderando el pathos del pasaje.

153 Il. XVI 259-262.

154 Respectivamente en $I l$. XXIII 88 y $O d$. VI 115 . Contra Gil, «El individuo y su marco...", p. 451, no se puede utilizar II. XIV 413 como prueba de que se conocía el juego de la peonza.

15s Il. XVIII 554-556. Cf. O. Taplin, "The Shield of Achilles within the Iliad", Greece and Rome, N.S. 27, 1980, p. 8, quien destaca el particular toque homérico de la escena.

156 Od. XX 209-210.

157 Od. XV $386-387$. 
Hay todavía en nuestros poemas dos escenas más de carácter infantil con desarrollo al aire libre que quiero traer aquí. Una es la bien conocida del simil de los niños que intentan impedir la entrada de un asno en campo de labor. Homero compara la persecución de Ayante Telamonio por los troyanos con un asno que entra en un sembrado y hace estragos en la mies, pese a que unos niños quieren impedirlo a varetazos; la fuerza de los pequeños es escasa, y cuando expulsan al asno, éste se ha cansado ya de comer ${ }^{158}$. El símil descansa sobre el testarudo animal, pero los verdaderos protagonistas son los chicos desolados, desaforados y sin cejar en su impotencia ante el desastre ${ }^{159}$. La otra escena pertenece a la descripción del escudo de Aquiles y es la de un niño,

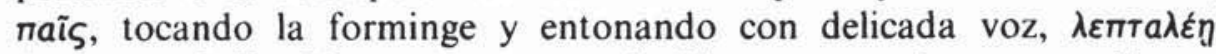
$\phi \omega v \tilde{n}$, un bello himno, un canto de Lino, que todos acompañan a coro $^{160}$. En ella es de destacar la referencia por parte del poeta a la peculiaridad que distingue una voz infantil, así como el simple hecho de entretenimientos musicales de este tipo. Otros pasajes homéricos aluden a coros de danza compuestos por gente joven, sean $\eta \hat{\imath} \hat{\imath} \varepsilon \circ$, sean кoũ sean коũ cia ${ }^{161}$. Aprovecho para añadir a esta mención de кoũ más que reflejan el mundo de la marcada juventud en nuestros poemas. Un pasaje representa a кoũ poเ discutiendo $\pi \varepsilon \rho i ~ \mu u ́ \vartheta \omega v$, es decir, lo que podría entenderse como leyendas, sabiduría atávica o simplemente oratoria ${ }^{162} ; \mathrm{y}$ dos más presentan juntos a muchachos ( $\left.\eta^{\prime} \hat{\imath} \vartheta \varepsilon o \iota\right)$ y muchachas

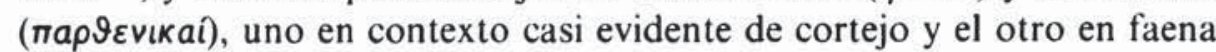
de vendimia sin que se descarte en trasfondo la dimensión sentimental. La primera escena es un diálogo de doncel y doncella desde una encina o desde una roca ${ }^{163}$, lo que invita a representarnos al muchacho encara-

15K II. XI 558-562.

159 Sobre este simil y su significado, Duchemin, "Aspects pastoraux...», p. 394 (con errata en la numeración de versos), y A. Schnapp-Gourbeillon, Lions, héros. masques. Les représentations de l'animal chez Homère. Paris 1981, pp. 76-77, la primera autora insistiendo en la dimensión del humor y la segunda en la inferioridad troyana.

${ }_{160}$ II. XVIII 569-572. Sobre el pasaje véase C. Calame, Les choeurs de jeunes filles en Grèce archaique, I: Morphologie, fonction religieuse et sociale. Roma 1977, páginas $79-80$ y $154-155$.

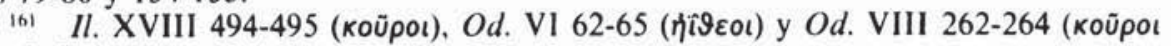

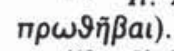

162 Il. XV 282-284.

163 II. XXII 126-128. Sobre la comparación, C. Gallavotti, «I documenti micenei e la poesia omerican, La poesia epica e la sua formazione. Accademia Nazionale dei Lincei, 367, 139, 1970, p. 86, y Moulton, Similes..., p. 82. La repetición de nap $9 \varepsilon v o \zeta$

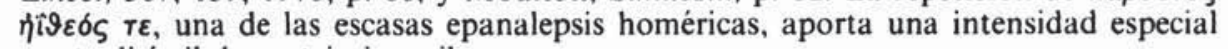
a este disimil de cortejo juvenil. 
mado y a la muchacha en el suelo. La segunda escena pertenece una vez más a la descripción del escudo de Aquiles y consiste en muchachos y muchachas vendimiadores, portando en cestos la uva y pensando en cosas árałá, es decir, juveniles, inconsistentes, ingenuas, delicadas o incluso tiernas en el sentido emocional del término ${ }^{164}$.

Quedan ya pocas cosas que decir. En primer lugar, que Homero puede atribuir al niño responsabilidades por encima de lo laboral; Aquiles niño, vímıs, fue enviado por Peleo como embajador, acompañado por Fénix ${ }^{165}$. En segundo lugar, la pederastia no tiene más representación en Homero que la indirecta mención del rapto del bello Ganimedes por Zeus y la compensación de éste mediante caballos a Tros, el padre del muchacho ${ }^{166}$. En tercer lugar, que la muerte infantil, escasamente presente en los poemas, parece que era tan antinatural para Homero, que, cuando el encuentro de Odiseo con los muertos, hay entre

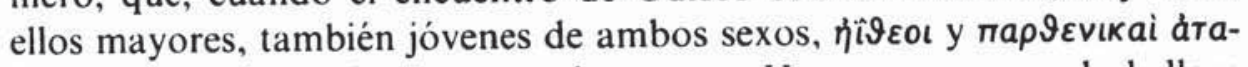
$\lambda a i$, pero no niños ${ }^{167}$. En cuarto lugar, que Homero reconoce la belleza infantil y adolescente, y la destaca ${ }^{16 \times}$. Por último, que a Homero le conmueve la niñez, como le conmueve todo lo pequeño. Ejemplos no faltan entre los pasajes citados anteriormente a otros efectos, aunque podría añadir dos más; uno referente a la infancia y otro del mundo animal: el pasaje de Eumeo niño, raptado y vagando ${ }^{169}$, y el de los pajarillos aterrorizados e indefensos, piando patéticamente ante la amenaza del

164 Il. XVIII 567. Sobre el adjetivo véase B. Mader, "átaAós", en Snell-Erbse (edd.), Lexikon des frühgriechischen Epos, cols. 1474-1475, con los usos en Homero, Hesiodo e himnos homéricos, así como la significación que apuntan los escolios, y

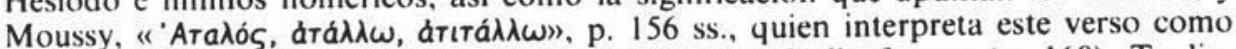
"des filles, des garçons qui ont la simplicité naïve de l'enfance" (p. 160). Taplin, "The Shield of Achilles», p. 8, señala que la misma cualidad que aqui se atribuye a

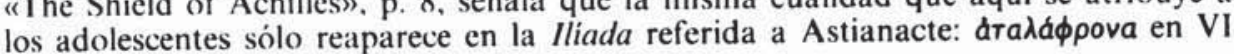
400 .

ins II. IX 438-441.

10* Il. V 265-266 y XX 232-235. Y, aun aqui, Homero prescinde de la dimensión erótica que al episodio atribuyen literatos y mitógrafos posteriores; cf. K. J. Dover, Greek Homosexuality, Londres 1978, pp. 196-197, y F. Buffière, Eros adolescent. La pédérastie dans la Gréce antique, París 1980, pp. 351-352. Respecto al pretendido amor de Aquiles y Patroclo, no hay evidencia de lo que algunos autores ven sugerido por Homero, por ejemplo W. M. Clarke, "Achilles and Patroclus in Love», Hermes 106. 1978, p. 381 Ss.; aparte de que ambos personajes, guerreros, se encontraban ya en una juventud adulta. Tampoco es indiscutible la interpretación del mismo autor de la relación entre Telémaco y Pisistrato, el hijo menor de Néstor, como pederastia sugerida (especialmente sobre $O d$. III 397-40I).

167 Od. XI 38-4I.

168 En Il. VI 401, compara al hijo de Héctor con una hermosa estrella; cf. Moulton, Similes..., p. 25 . En II. XXIV $347-348$ y Od. X 277-279, se refiere a la adolescencia como ideal de belleza masculina.

${ }_{169}$ Od. XV 381-382. 
reptil que les va devorando uno a uno ${ }^{170}$. Y, si aduzco este segundo ejemplo, es porque nuestro poeta acerca no poco las dimensiones animal y humana, cual se ve en abundantes símiles y en referencias marginales, como el que pueda decir de unas yeguas que han pasado ya de la veót S $^{171}$. Las reacciones solidarias de Homero con los animales pequeños son reflejo de los sentimientos que abriga en relación con el hombre en sus más jóvenes edades.

Con lo dicho queda recogido lo fundamental que en Homero hay sobre la niñez y la juventud inmadura. El muy diferente carácter de uno y otro poema motiva dos realidades que saltan a la vista: la primera es que no aportan elementos relativos a la menor edad en equilibrio proporcional a sus respectivos números de versos - la Iliada es absoluta y relativamente más rico que la Odisea, y eso a pesar de que es un relato de guerra y los menores no participan en ella-; la segunda es que el contexto, tenor e intención de los datos contrasta de forma bien visible entre ambos poemas. Hay como una especialización. Troya, la ciudad sitiada, tiene sus niños y muchachos dentro, con las mujeres y los ancianos; en uno y otro bando hay guerreros que rememoran la más o menos lejana niñez; y además, es factor significativo, la Ilíada presenta una muy superior utilización del símil que la Odisea ${ }^{172}$, y son frecuentes las alusiones a los pequeños o aplicables a ellos en este típico recurso de los poemas homéricos ${ }^{173}$. La Odisea relata las complicadas andanzas por mar del protagonista y sus compañeros, cosa que no excluye el recuerdo de la propia niñez, aunque sí la presencia directa de lo infantil; y no deja de extrañar que los a veces dilatados episodios palaciegos - Telémaco en Pilo y en Esparta, Odiseo en la corte de Alcínoo y en Ítacasean tan parcos en referencias a los menores. Diferencia, pues, en el número de datos y diferencia también en su carácter y utilización. Pero, por una parte, la complementariedad que of recen es enriquecedora; por otra, ya lo dije al principio, hay algo sobre lo que importa a nuestro tema en lo que coinciden los dos poemas: presentan más cuadros de vida y psicología rudimentaria que otra cosa. Lo cual en Homero no extraña en absoluto.

\section{Luis García Iglesias}

\footnotetext{
170 Il. II 311-315.

171 Il. XXIII 445.

172 Véase D. J. N. Lee, The Similes of the "Iliad" and the "Odyssey" compared, Melbourne 1964, pp. 3-5, y los cuadros finales de Scott, The Oral Nature..., p. 191.

${ }_{173}$ La Odisea presenta, sin embargo, un cierto número de símiles con el tema de la relación padre-hijos, estudiados conjuntamente por Moulton, Similes..., páginas $141-145$.
} 